\title{
A GESTÃO DA ARBORIZAÇÃO URBANA NA CIDADE DE PASSO FUNDO/RS
}

\author{
Evanisa Fátima Reginato Quevedo Melo; Anicoli Romanini²
}

\section{RESUMO}

Passo Fundo, localizada na região norte do Rio Grande do Sul, é uma cidade de porte médio, que teve um significativo desenvolvimento urbano, mas que, mesmo assim, ocorreu de forma desordenada, principalmente em relação à infra-estrutura social. Logo, a gestão da arborização se torna um fator importante para a correta utilização das áreas verdes, intimamente relacionada com a quantidade, a qualidade e a distribuição das mesmas dentro da malha urbana. Assim, buscou-se desenvolver nesse trabalho definições para o planejamento da arborização urbana. Deste modo, este estudo tem o objetivo de estabelecer o índice quantitativo de áreas verdes públicas disponíveis na cidade de Passo Fundo/RS, em relação ao espaço edificado, expressando a quantidade de espaços livres de uso público, em $\mathrm{m}^{2}$, pela quantidade de habitantes. As áreas verdes analisadas referem-se ao predomínio de vegetação arbórea, englobando as praças, os parques urbanos, os canteiros centrais de avenidas e as calçadas de algumas vias públicas selecionados em função da presença da vegetação. Constata-se que a cidade possui uma quantidade de vegetação próxima, mas abaixo dos parâmetros exigidos, segundo a bibliografia existente, além de uma má distribuição e localização desses espaços, não atendendo as mínimas necessidades para atividades físicas e de lazer.

Palavras-chave: Arborização Urbana, Áreas Verdes, Planejamento Urbano, Gestão Urbana.

\footnotetext{
${ }^{1}$ Engenheira Florestal e Agrônoma, Doutora em Agronomia, Universidade de Passo Fundo, Passo Fundo, RS, evanisa@upf.br

${ }^{2}$ Arquiteta e Urbanista, Mestranda em Infra-estrutura e Meio Ambiente, Universidade de Passo Fundo, Passo Fundo, RS, arquiteta_anicoli@yahoo.com.br
} 


\title{
THE MANAGEMENT OF THE URBAN ARBORIZATION IN THE CITY OF PASSO FUNDO/RS
}

\begin{abstract}
Passo Fundo, located in the north region of the Rio Grande Do Sul, has about 180.000 inhabitants and its urban development occurred of disordered form, mainly in relation to the social infrastructure. The management of the arborization becomes an important factor for the correct use of the green areas, related with the amount, the quality and the distribution of the same ones inside of the urban mesh. Then we intend searched to develop, in this work, definitions for the planning of the urban arborization. In this way, this study has the objective to establish the quantitative index of available public green areas in the city of Passo Fundo/RS, in relation to the built space, expressing the amount of free public spaces, in $\mathrm{m}^{2}$, for the amount of inhabitants. The analyzed green areas mention the predominance of it about arboreal vegetation, considering the urban squares, parks, the seedbeds central offices of avenues and the sidewalk of some public ways chosen in function of the presence of the vegetation. It evidences that the city has an amount of vegetation index, but below of the demanded parameters, according to existing bibliography, beyond an bad distribution and localization of these spaces, farway of the minimum necessities for physical activities and of leisure.
\end{abstract}

Key- Words: Urban Arborization, Green Areas, Urban Planning, Urbana Management. 


\section{INTRODUÇÃO}

As cidades de um modo geral passaram a ter um papel cada vez mais significativo no planeta, tanto em termos quantitativos como qualitativos. Ressalta-se, principalmente nos países periféricos, como o Brasil, a necessidade de novas estruturas e formas urbanas para fazer face aos problemas que vêm se acumulando dramaticamente. É preciso repensar as cidades, sob a ótica da justiça social, da qualidade de vida urbana, da gestão ambiental e da governabilidade, refazendo novas práticas de construção da cidade em substituição à urbanização tradicional.

De acordo com a cultura local e o modo de produção da cidade, este se constitui o maior agente causador de impactos sobre a natureza. $\mathrm{O}$ modo de produção capitalista, caso das cidades brasileiras, faz com que estas cresçam de forma desmesurada e acabem assim por estrangular as áreas verdes que entremeavam o ambiente urbano (FEIBER, 2004).

De acordo com CARVALHO (2003):

Ao longo da história brasileira, curta, mas com intensas transformações, a natureza foi vista pelos urbanizadores, tradicionais e orgânicos, de modo bastante diferenciado, determinado por culturas variadas e por modos de produção que realizam o território segundo suas leis de reprodução. De início, embora em pequena escala, e com poucos impactos, a natureza foi destruída sistematicamente, dispersadamente no território brasileiro. Sob a égide do modo de produção capitalista, as cidades cresceram desmesuradamente e estrangularam as áreas verdes e os rios que entremeavam os bairros das cidades

Logo, a arborização urbana tem grande importância na melhoria das condições de vida nos centros urbanos. Com o crescimento populacional das cidades, as mesmas deparam-se com a falta de um planejamento urbano organizado e bem estruturado.

Segundo CARVALHO (2003):

O urbanismo no final do século XIX, sob influência européia, busca algumas medidas no sentido de abrandar o problema com a implantação de passeios e jardins públicos. Estas ações mitigadoras colocam as áreas verdes como agentes responsáveis pelo resgate do bem-estar da população. 
Assim, Passo Fundo, situada no norte do estado do Rio Grande do Sul, conta com uma população estimada de $182.233^{3}$ habitantes, é considerada um pólo de desenvolvimento sócio-econômico, com localização privilegiada dentro do Mercosul, no centro dos eixos econômicos de Buenos Aires, Montevidéu e São Paulo - Rio de Janeiro, permitindo um rápido acesso às capitais do sul do Brasil e países vizinhos.

Em 2005, a cidade ostenta a privilegiada condição de pólo cultural, consolidando eventos importantes de nível nacional e internacional. Possui uma rede hospitalar que é reconhecida como referência em todo o estado. No setor educacional, a cidade conta com uma Universidade com título de Universidade Comunitária Regional, que possui mais de 16 mil acadêmicos e colabora com o desenvolvimento que vai além do município. Com um comércio expressivo e aperfeiçoando constantemente sua infra-estrutura é considerada uma das mais importantes do Estado, destacando-se como prestadora de serviços.

Assim, esse estudo tem o objetivo de estabelecer o índice quantitativo de áreas verdes públicas disponíveis na cidade de Passo Fundo/RS em relação ao espaço edificado, ou seja, busca expressar a quantidade de espaços livres de uso público, em $\mathrm{m}^{2}$, pela quantidade de habitantes.

\section{Áreas Verdes}

A natureza, em parte representada nas áreas verdes, precisa ser repensada no sentido da valorização do seu papel no funcionamento/metabolismo da cidade. É preciso definir o quanto deve ser preservado, conservado, transformado ou reconstruído para a consecução de ambientes agradáveis e sadios que propiciem uma rica vida de interações sociais e gestão ambiental equilibrada. Todos os verdes precisam ser identificados, classificados e catalogados de forma consoante às necessidades urbanas, desde a provisão de parques públicos, áreas de contenção, armazenamento de águas pluviais, abastecimento d'água, até a produção de alimentos. Para tanto, são necessários estudos quantitativos e qualitativos para determinar o seu dimensionamento e as funções de cada área verde (CARVALHO, 2003).

Há uma dificuldade de entendimento em relação aos diferentes termos utilizados sobre as áreas verdes urbanas. Similaridades e diferenciações entre termos como áreas livres, espaços abertos, áreas verdes, sistemas de lazer, praças, parques urbanos, unidades de conservação em área urbana, arborização urbana e tantos outros, confundem os profissionais que trabalham nessa área. Esse problema existe nos níveis de pesquisa, ensino, planejamento e gestão dessas áreas. Nesse sentido, buscou-se desenvolver nesse trabalho definições para esses termos, a fim de obter uma melhor compreensão e distinção destes assuntos. Abaixo seguem algumas definições:

\footnotetext{
${ }^{3}$ População estimada para 2004, segundo IBGE.
} 
Arborização Urbana: Refere-se aos elementos vegetais de porte arbóreo, dentro da cidade. Nesse enfoque, as árvores plantadas em calçadas, fazem parte da arborização urbana, porém, não integram o sistema de áreas verdes. Segundo Tomasini (1998, p.62) a arborização de uma cidade é composta, essencialmente, de árvores localizadas em área particulares e árvores localizadas em áreas públicas, dividindo-se, essas últimas, ainda, entre aquelas que estão situadas em áreas verdes e aquelas situadas em vias públicas. Compreende as árvores existentes nas vias públicas, mais especificamente nos passeios públicos. Mas não é tão simples como parece, segundo Haas (1999) a árvore deve satisfazer tanto aos interesses do morador da residência em frente a qual se localiza, quanto aos interesses da comunidade como um todo. A ação de plantar uma árvore deve ser precedida de uma preparação, seguindo um roteiro adequado e determinado. A solução precisa ser estudada e aplicada para cada cidade isoladamente, aumentando a complexidade na proporção em que as cidades se desenvolvam.

Área Verde: Local onde há o predomínio de vegetação arbórea, englobando as praças, os jardins públicos e os parques urbanos. São os canteiros centrais de avenidas, os trevos e rotatórias de vias públicas, que exercem apenas funções estéticas e ecológicas. "São espaços livres nas cidades, com características predominantemente naturais, independentemente do porte da vegetação e da sua origem - nativa, introduzida ou exótica" (PUPPI, 1981; HARD, 1999, 2002). Conceituadas por Holanda Ferreira (1986, apud HARD, 2002, p.29) como a "extensão de terreno com vegetação". As áreas verdes urbanas podem ser interpretadas sob duas abordagens: de forma geral, como sistema de áreas verdes urbanas, e, de maneira específica, como espaços verdes individuais (HARD, 1994, 2002, p.29).

Parque Urbano: Área verde localizada dentro do perímetro urbano, com uma maior extensão do que as praças e jardins públicos, e funções ecológicas, estéticas e de lazer. De acordo com Menezes (1996) os parques têm sido construídos como uma alternativa para diferentes necessidades da cidade, apresentando-se como locais de lazer e novos pontos de encontro entre os habitantes, mas também projetados para evitar a habitação nos fundos de vale, preservar as matas ciliares e regular a vazão dos rios em períodos de enchentes.

Praça: Área verde que tem como função principal, o lazer. Uma praça, inclusive, pode não ser uma área verde, quando não tem vegetação e encontra-se impermeabilizada. Mello e Cañelas (2000) descrevem praças como parcela do território urbano configurando um espaço público. Do ponto de vista urbanístico, a praça se caracteriza pelo contraste com a malha urbana que a cerca, é um vazio no meio de cheios, quebra a continuidade dos quarteirões edificados, introduz um elemento de surpresa e descontração. 


\section{Planejamento e Legislação}

A legislação de parcelamento do solo dos municípios usualmente exige doação de 10 a 15\% de áreas verdes com relação ao total da gleba, sem exigir a implantação de praças e outros equipamentos nos espaços previstos. Supõe-se que esses espaços seriam gradativamente equipados, pela própria municipalidade. Na prática, freqüentemente as áreas reservadas são impróprias para este fim e têm sido ocupadas por favelas. Torna-se, assim, necessária uma revisão da política pública relativa à capacitação das áreas verdes, que não pode se restringir à discussão do seu dimensionamento (MORETTI, 1997, p.131).

O Código de Áreas Verdes e a Arborização Urbana de uma cidade é o instrumento legal e de gerenciamento mais importante que pode haver para se assegurar à existência de espaços que desempenham funções de melhorias do ambiente urbano e da qualidade de vida dos seus habitantes.

Quanto ao planejamento, deve-se pensar primeiramente na cidade como um todo, propondo a existência e funcionalidade de um sistema municipal de áreas verdes ou de espaços livres, considerando a densidade populacional dos bairros ou setores da cidade e o potencial natural das áreas existentes.

Quanto à legislação, citam-se a seguir aquelas que devem merecer atenção para o desenvolvimento de trabalhos com áreas verdes e arborização urbana:

$\Rightarrow$ Lei 7.803/89, alterando a Lei 4.771/65 que estabelece o Código Florestal Brasileiro;

$\Rightarrow$ Lei 6.766/79 que dispõe sobre o parcelamento do solo urbano;

$\Rightarrow$ Lei Orgânica do Município;

$\Rightarrow$ Plano Diretor do Município e leis complementares, como Código Municipal de Meio Ambiente, Lei Municipal de Parcelamento e Uso do Solo Urbano, Plano Viário Municipal, Lei do Mobiliário Urbano e Lei Municipal de Saneamento.

As áreas verdes desempenham um papel fundamental na concepção das cidades, interferindo em elementos importantíssimos da ocupação territorial, do clima, variação de temperatura, umidade relativa do ar, enfim nas características de cada local. Com isso esse trabalho tem por objetivo fazer um levantamento quantitativo das áreas verdes urbanas existentes no município de Passo Fundo, na busca da suficiente equivalência com o espaço edificado, e verificar se há um índice adequado de arborização em relação às necessidades dos habitantes na malha urbana, objeto de relevante importância para a qualidade urbana.

\section{MATERIAIS E MÉTODOS}


Localizada no Planalto Médio, ao norte do Estado do RS, Passo Fundo está a 287 $\mathrm{Km}$ distante da capital gaúcha (Figura 01). Com uma altitude de $687 \mathrm{~m}$ acima do nível do mar, possui densidade demográfica de 205 hab/ $/ \mathrm{Km}^{2}$ em uma área de 708,4 Km². O clima é temperado com características subtropical úmido e temperatura média anual de $17,5^{\circ} \mathrm{C}$, sendo que a temperatura média do mês mais quente (Janeiro) chegou a $22,9^{\circ} \mathrm{C}$ e a temperatura média do mês mais frio (Junho) a $12,7^{\circ} \mathrm{C}$, com umidade relativa do ar (média anual) de $72 \%$.

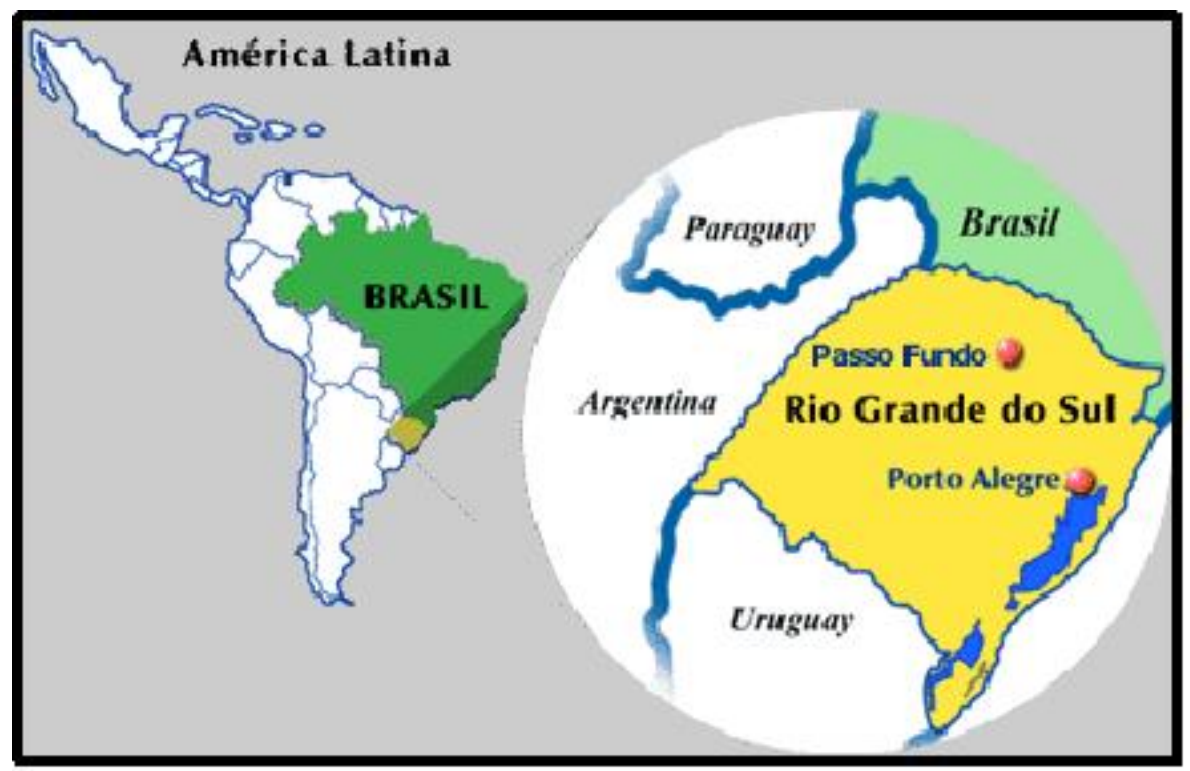

Figura 01. Localização da cidade de Passo Fundo, mapa do Brasil.

Fonte. Prefeitura Municipal de Passo Fundo/RS, 2005.

A caracterização da área de estudo se deu através da análise de fotos aéreas (urbanas) de Passo Fundo, mapas e plantas atualizadas da cidade e observações de campo (in situ). Com o levantamento de campo, chegou-se a dados quantitativos das áreas verdes relevantes, apoiados ainda, em estudos já realizados na bibliografia existente. As áreas verdes citadas nessa análise referem-se ao predomínio de vegetação arbórea, englobando as praças, os parques urbanos, os canteiros centrais de avenidas e as calçadas de algumas vias públicas importantes.

\section{RESULTADOS E DISCUSSÕES}

Integrando-se à estrutura global de planejamento, o Planejamento Municipal pode ser visto como uma explicitação dos planos regionais tendendo às peculiaridades de cada município e adequando a sua estrutura interna de organização às necessidades do desenvolvimento regional, dentro de um planejamento global. O planejamento no nível dos municípios assume, então, características integrais, uma vez que cabe a administração local 
o atendimento de necessidades múltiplas, tanto no campo sócio-econômico, como no físicoterritorial e no institucional-administrativo (BRUNA, 1983, p.265).

A Lei de Urbanismo e Zoneamento do I Plano Diretor, elaborada por Paiva et al. (1950), revela a preocupação do governo municipal em reordenar o núcleo urbano, direcionando suas melhorias e seu crescimento. Essa lei estabelece critérios para a reorganização do espaço urbano e público existente, em termos de abertura e de retificação do sistema viário, propondo a construção de um centro cívico, de um mercado público, de um estádio municipal, dentre outros. Também fixa diretrizes para a expansão e o estabelecimento de novos loteamentos em áreas não abrangidas inicialmente, salientando alguns pontos relevantes:

a) reloteamento de áreas vacantes, com abertura ou alargamento de praças, logradouros e vias públicas;

b) novos arruamentos em terrenos apropriados, com serviços públicos (água, ruas com cordões, sarjetas e pavimentação de macadame) e em funcionamento, executados à custa do proprietário, exigindo, inclusive, a aprovação dos projetos de loteamento, de redes de água e de pavimentação pelo órgão técnico da prefeitura municipal (DAL MORO et al., 1998, p.94).

Segundo Diehl (1998), o embelezamento de praças e logradouros já fazia parte da proposta cultural da cidade de Passo Fundo, em 1908 a Intendência Municipal destinava uma área de terra para a praça Marechal Floriano. Em 1920, começava o trabalho de ajardinamento, colocação de bancos e pavimentação dos passeios revestidos de mosaicos, além da construção de um quiosque para encontros sociais. Em 1925, foi meta o embelezamento da Praça Tamandaré também com a construção de um quiosque, canteiros de flores e de uma coluna para colocação de uma bomba para depósito e distribuição de água. $\mathrm{Na}$ área urbana da cidade, o núcleo central e seu entorno receberam melhorias na infra-estrutura, calçamento, iluminação pública e abastecimento de água, coleta de lixo e ampliação da rede escolar. Segundo o autor, "o setor de construção civil crescia e renovava a paisagem urbana, embora isso não significasse que a expansão urbana tivesse ocorrido de modo ordenado e harmonioso".

O crescimento das cidades conforme Requixa (1977) "ocorre em virtude dos anseios e necessidades de seus próprios habitantes". O que está havendo, é uma falta de previsão quanto ao crescimento desordenado da cidade, ocasionando que o individuo usufrua uma vida de acordo com as suas estruturas em busca da melhor forma possível, em suprir suas necessidades, mais próxima de si. Já segundo Bruna (1983, p.266), para o planejamento municipal atender suas finalidades, ele "deve objetivar o estudo da realidade do Município, visando ao seu desenvolvimento integral, à ordenação e ao controle de suas estruturas, à ampliação de suas fontes de recursos e à otimização da atividade administrativa". 
Pela ausência de um planejamento urbano, na gênese do município, a cidade cresceu desordenadamente. Segundo Oliveira (2004, p.26), esse "crescimento desordenado (como na maioria das cidades nas últimas décadas), desenvolveu a cidade de maneira desorganizada e com graves descuidos ambientais". Assim, a infra-estrutura básica não é suficiente para suprir a demanda, nem os meios de planejamento e controle da cidade são especificados diante da necessidade atual, pois com os planos diretores arcaicos e, no entanto inadequados, ocorre uma degradação ambiental cujo aspecto mais evidente está relacionado com o uso da terra. A área central da cidade de Passo Fundo possui uma população acima de 25 hab/ha (figura 02), isso demonstra a concentração populacional e, 'explica' a massa edificada desses locais.

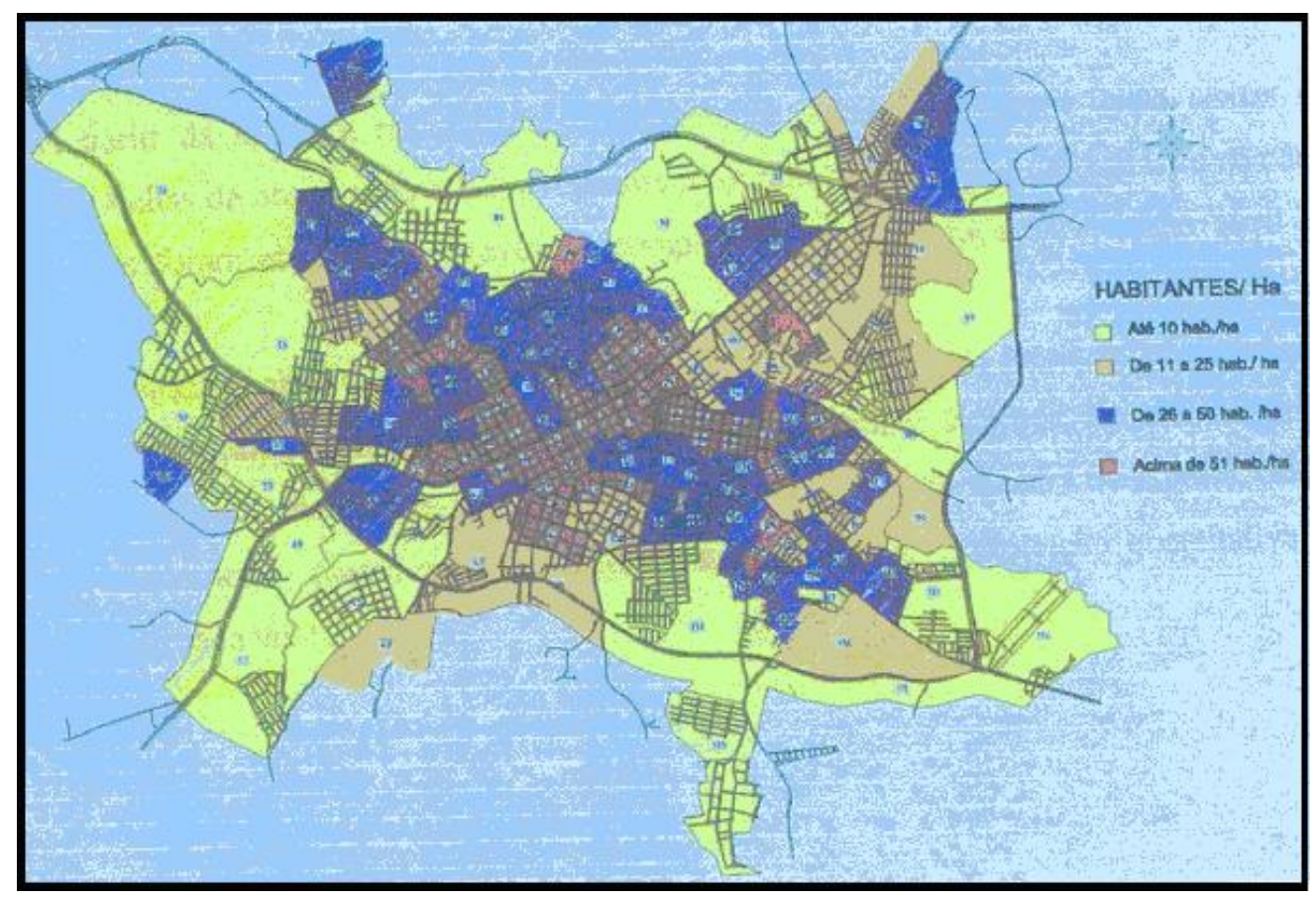

Figura 02. Mapa da ocupação do território da cidade de Passo Fundo/RS.

Fonte. OLIVEIRA, 2004, p.26.

Passo Fundo (Figuras 03 e 04) possui uma área de aproximadamente 120.000.000 $\mathrm{m}^{2}$ de área urbana e 180.000 hab. Segundo dados do IBGE (2001), a cidade possui 49.529 domicílios, portanto admite-se que Passo Fundo possui um índice de 3,40 habitantes por unidade habitacional, ou seja, uma população menor em relação aos dados de Moretti (1997, p.137). Segundo o autor, é necessário uma avaliação da área verde disponível para cada habitante e para cada habitação, em função da densidade populacional, supondo-se 10 e $15 \%$ do território para áreas verdes e 4 habitantes por unidade habitacional. 

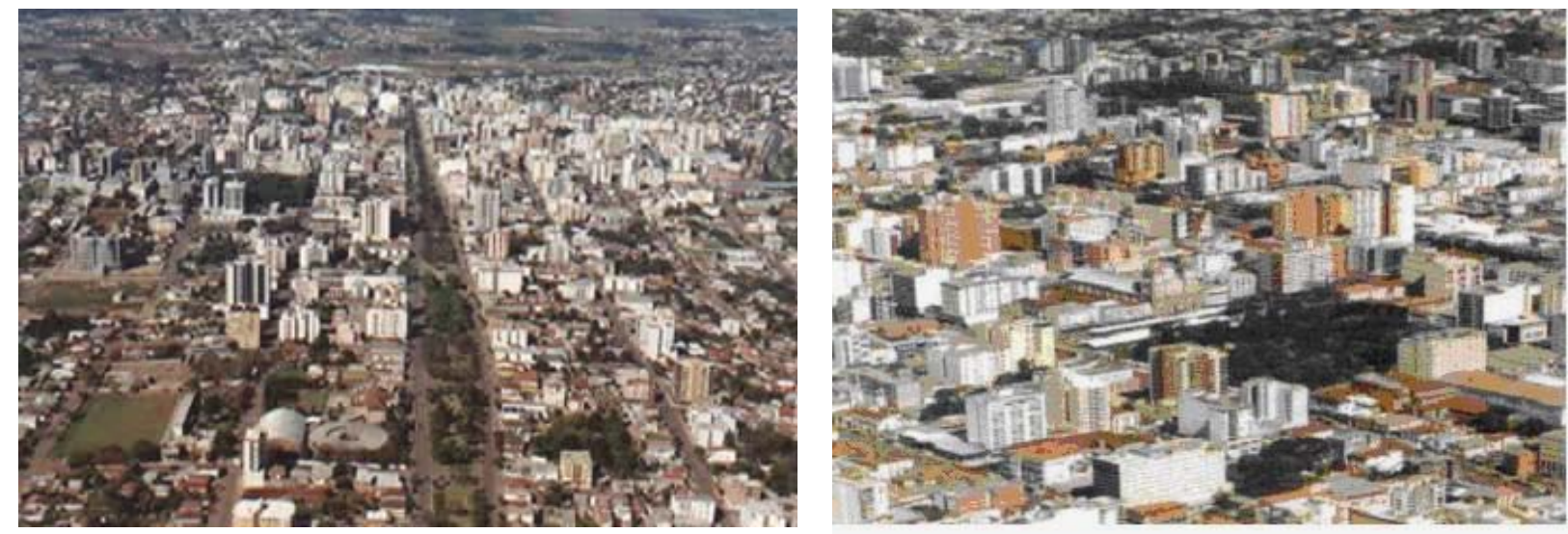

Figuras 03 e 04. Vistas aéreas da cidade de Passo Fundo.

Fonte. Prefeitura Municipal de Passo Fundo, 2005.

Conforme Moretti (1997, p.136) as "áreas verdes" incluem espaços com funções bastante distintas, assim "o papel do Poder Público na decisão sobre a seleção desses espaços, em cada caso, deve ser avaliado". Já a localização dessas áreas verdes, em especial as praças e demais referenciais urbanos e paisagísticos "deve ser parte intrínseca do projeto do assentamento habitacional e seria desejável que a municipalidade não assumisse uma postura inibidora da criatividade dos projetistas neste aspecto". Infelizmente, o autor ainda diz, que "o que se observa nos projetos de parcelamento é a total desconsideração pelos espaços públicos, que freqüentemente são os terrenos mais problemáticos existentes na gleba". Ainda complementa que seria necessária a participação do poder público municipal na definição relativa à localização das praças, como forma de evitar as distorções hoje observadas: "a possibilidade de indicação das áreas públicas, por ocasião do fornecimento das diretrizes municipais, constitui alternativa para esta definição".

Magalhães (1996, p.95) garante que a implantação dos espaços de lazer deve ser planejada de forma global para toda a área do bairro e seu entorno, qualificando e dimensionando as carências a partir dos equipamentos existentes e das demandas da população.

No trabalho "Elementi di Urbanística" (DODI, 1953 apud MORETTI, 1997, p.134), o autor identifica seis categorias para analisar a forma de como são classificadas as áreas verdes com características distintas: áreas verdes de pequenas dimensões nas calçadas, canteiros centrais de vias e jardins de residências, áreas verdes ornamentais de edifícios públicos, áreas verdes de proteção e separação (proteção a monumentos, separação de ferrovias, indústrias, etc), jardins e praças públicas, parques públicos (de grandes dimensões, com caráter rural e regional, campos de jogos e zonas esportivas (muitas vezes incorporados às categorias anteriores e com raio de atendimento diferenciado para diversas faixas etárias). Dentro deste perímetro, o levantamento das áreas verdes da cidade, foi feito 
com a distinção de quatro tipos básicos de sistemas (Figura 05):

\section{Arborização Urbana:}

$\Rightarrow$ Calçadas da Av. Brasil,

$\Rightarrow$ Calçadas da Av. Presidente Vargas,

$\Rightarrow$ Calçadas da Av. Scarpelini Ghezzi,

$\Rightarrow$ Calçadas da Rua Morom.

\section{Área verde:}

$\Rightarrow$ Canteiros Centrais da Av. Brasil,

$\Rightarrow$ Canteiros Centrais da Av. Presidente Vargas,

$\Rightarrow$ Canteiros Centrais da Av. Rui Barboza,

$\Rightarrow$ Canteiros Centrais da Av. Scarpelini Ghezzi,

$\Rightarrow$ Canteiros Centrais da Rua General Neto.

\section{Parque Urbano:}

$\Rightarrow$ Parque da Gare.

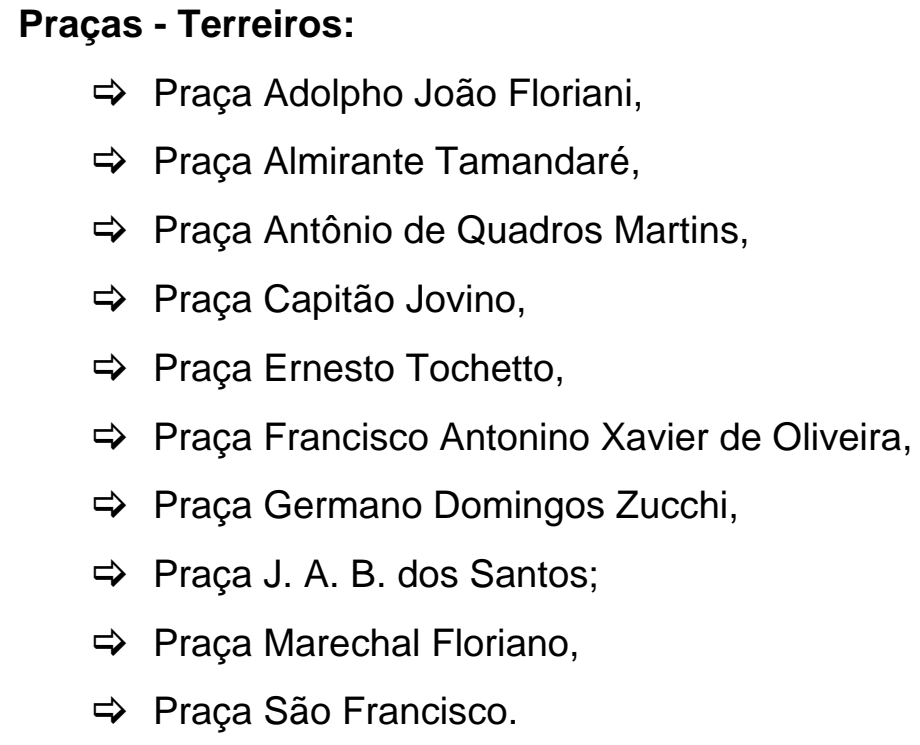




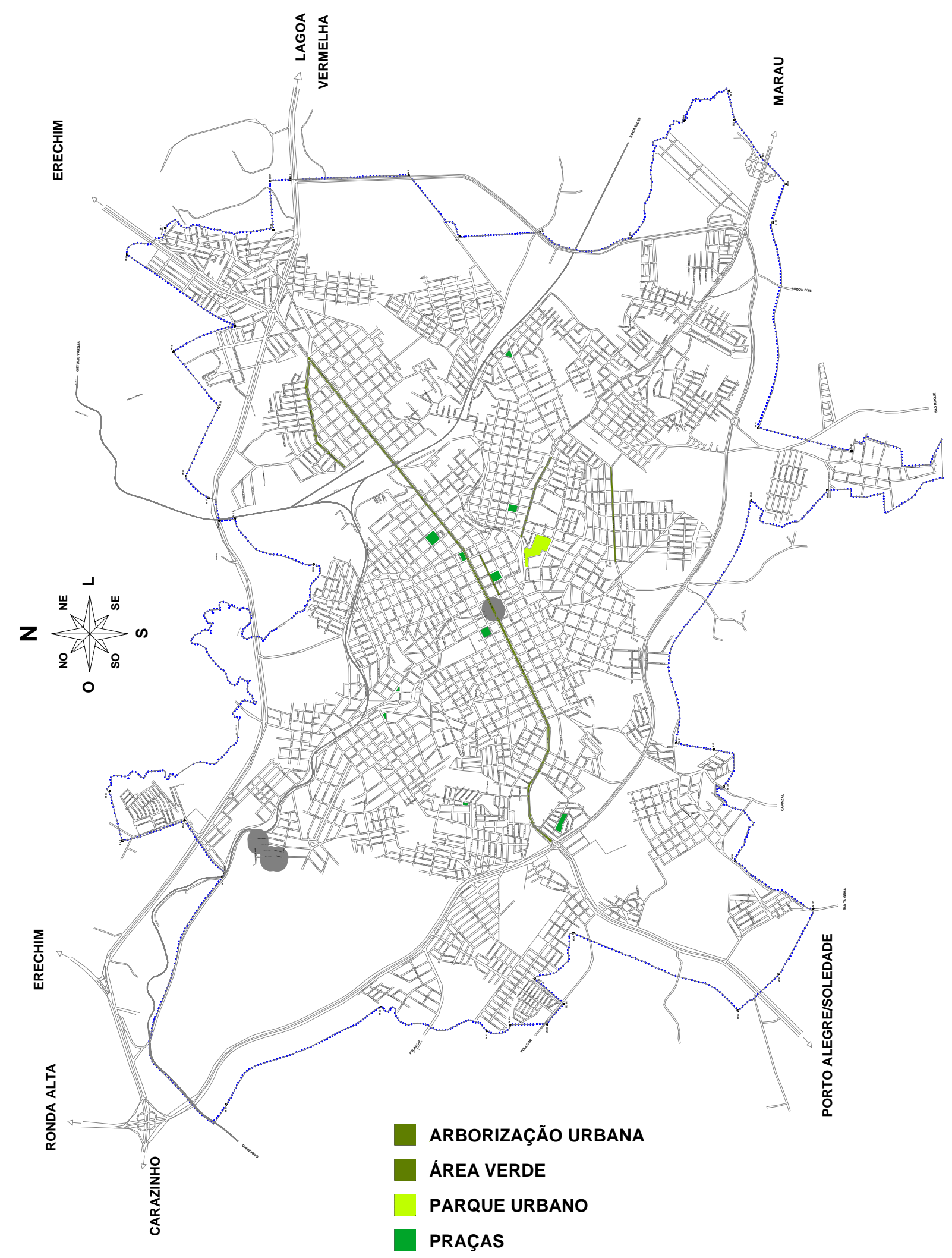

Figura 05. Mapa com definição das áreas verdes da cidade de Passo Fundo/RS.

Ainda, em relação ao dimensionamento de áreas verdes, cabe destacar a grande discrepância dos números apontados na literatura. Moretti (1997, p.137) cita que o índice de 
metros quadrados de área verde por unidade habitacional varia entre 6,00 (Garden-Robert), 24,00 (Dodi) e 48,00 (ONU - supondo 4 habitantes por unidade habitacional). De fato é bastante difícil estabelecer qual a quantidade de áreas verdes públicas que deve ter uma cidade. Deve ser ainda lembrada a confusão de conceitos quanto à definição de que tipo de área verde entra nesse cômputo.

Assim, apresenta-se na tabela 01 uma avaliação da área verde disponível para cada habitante e para cada habitação, em função da densidade populacional:

Tabela 1. Área verde disponível em função da densidade.

\begin{tabular}{|c|c|c|c|c|c|}
\hline \multicolumn{2}{|c|}{ Densidade } & \multicolumn{2}{c|}{$10 \%$ de área verde } & \multicolumn{2}{c|}{$15 \%$ de área verde } \\
\hline $\begin{array}{c}\text { Unidades } \\
\text { habitacionais } \\
\text { por hectare }\end{array}$ & $\begin{array}{c}\text { Habitacionais } \\
\text { por hectare }\end{array}$ & $\begin{array}{c}\text { A. V. por } \\
\text { unidade } \\
\text { habitacional } \\
\left(\mathrm{m}^{2}\right)\end{array}$ & $\begin{array}{c}\text { A. V. por } \\
\text { habitante } \\
\left(\mathrm{m}^{2}\right)\end{array}$ & $\begin{array}{c}\text { A. V. por } \\
\text { unidade } \\
\text { habitacional } \\
\left(\mathrm{m}^{2}\right)\end{array}$ & $\begin{array}{c}\text { A. V. por } \\
\text { habitante } \\
\left(\mathrm{m}^{2}\right)\end{array}$ \\
\hline 20 & 80 & 50,0 & 12,5 & 75,0 & 18,75 \\
\hline 40 & 160 & 25,0 & 6,2 & 37,5 & 9,4 \\
\hline 60 & 240 & 16,7 & 4,2 & 25,0 & 6,2 \\
\hline 80 & 320 & 12,5 & 3,1 & 18,7 & 4,7 \\
\hline 100 & 400 & 10,0 & 2,5 & 15,0 & 3,7 \\
\hline 150 & 600 & 6,7 & 1,7 & 10,0 & 2,5 \\
\hline 200 & 800 & 5,0 & 1,2 & 7,5 & 1,9 \\
\hline
\end{tabular}

Fonte. MORETTI, 1997

$\mathrm{Na}$ realidade pode-se falar em diferentes índices para expressar o verde nas cidades. O índice de áreas verdes é aquele que expressa a quantidade de espaços livres de uso público, em $\mathrm{m}^{2}$, pela quantidade de habitantes que vivem em uma determinada cidade. Então, neste cômputo, entram as praças, os parques urbanos, os canteiros centrais de avenidas e as calçadas de algumas vias públicas relevantes, ou seja, aqueles espaços cujo acesso da população é livre.

Segundo Cavalheiro \& Del Picchia (1992), é importante comentar que está difundida e arraigada no Brasil a assertiva de que a ONU, ou a OMS, ou a FAO, considerariam ideal que cada cidade dispusesse de $12,00 \mathrm{~m}^{2}$ de área verde/habitante. "Nas pesquisas, feitas junto a essas Organizações, foi constatado que esse índice não é conhecido, como não o é, entre as faculdades de paisagismo da República Federal da Alemanha". O autor ainda diz que, depois de terem realizado muitos estudos, supõe-se que "esse índice se refira, tão somente às necessidades de parque de bairro e distritais/setoriais, já que são os que, dentro da malha urbana, devem ser sempre públicos e oferecem possibilidade de lazer ao ar livre".

A análise do estudo demonstra que a cidade de Passo Fundo possui aproximadamente $2.000 .000 \mathrm{~m}^{2}$ de áreas verdes, o que faz com que a cidade tenha 
aproximadamente $16 \%$ de espaço verde em relação à área urbana, e 11,11\% de área verde por habitante. O município possui 49.529 unidades habitacionais, diante disso, chega-se ao índice de metros quadrados de área verde por unidade habitacional que equivale a 40, portanto segundo especificações acima, este valor está dentro dos parâmetros esperados segundo Moretti (1997), entretanto, abaixo dos índices que a ONU, ou a OMS, ou a FAO, consideram ideal, citado por Cavalheiro \& Del Picchia (1992).

$\mathrm{Na}$ arborização urbana, deve-se conhecer o ambiente, espaço físico disponível, as características locais e também as características das espécies utilizadas (MILANO, 1984). Do mesmo modo, percebe-se como a vegetação constituiu um elemento fundamental para proporcionar um agradável bem estar a população, segundo Rodrigues (1986, p.54) a presença da sombra - no caso um 'oásis de conforto' após algum percurso em condições adversas de temperatura - continua sendo importante no uso da cidade, da rua, pois é aí que as pessoas param para uma conversa ou por aí que pessoas caminham em regiões de clima quente.

De acordo com Gelpi e Rossetto (1999, p.20 e 21), não é mais questionável que as árvores e áreas verdes do ambiente urbano proporcionam uma melhoria de qualidade ambiental ao atuar como elementos corretores de certas fontes consideradas nocivas, "conseguindo que as condições do meio aproximem-se daquelas consideradas como satisfatórias ou normais".

Considerando o meio urbano atual é preciso manter o equilíbrio ambiental e melhorar as condições de vida da população. Conforme Corazza (2003, p.13) junto a esta unidade de caráter físico, cita-se também o psicológico, já que uma das principais causas da presença de áreas verdes é o desejo de ar puro. Assim, pode-se afirmar que a vegetação contribui para a regeneração do meio urbano e, por conseguinte, restabelece o equilíbrio psicossomático do homem.

\section{CONCLUSÕES}

Através da quantificação das áreas verdes de Passo Fundo, percebeu-se que a cidade possui uma quantidade de vegetação próxima, mas abaixo dos parâmetros exigidos segundo Moretti, porém com uma má distribuição e localização desses espaços, não atendendo as mínimas atividades físicas e de lazer. No entanto, por serem os valores de pequena diferença, o recomendável seria a criação de novos espaços, mas principalmente, de outros mananciais que ainda estejam disponíveis no perímetro urbano do município, entretanto essas áreas verdes devem ser disciplinadas para que cumpram as suas finalidades. 
O crescimento das áreas verdes deve ser proporcional ao crescimento das cidades, para que estas permitam condições ideais de vida aos seus habitantes, bem como a disponibilidade de espaços para recreação e prática de esporte nas cidades não depende exclusivamente da existência de áreas para o desenvolvimento dessas atividades. A conservação e manutenção de todos os elementos que compõem uma praça ou um parque ou uma rua ou avenida, devem merecer atenção continuada dos órgãos públicos que gerenciam essas áreas e da população que as utilizam, pois seu uso está intimamente ligado à localização, manutenção, conservação e segurança que esta área recebe.

\section{REFERÊNCIAS BIBLIOGRÁFICAS}

BRASIL. Lei $n^{0} 6.766$, de 19 de dezembro de 1979, dispõe sobre o parcelamento do solo urbano e dá outras providências. Congresso Nacional, Brasília, 19 de dezembro de 1979; $158^{\circ}$ da Independência e $91^{\circ}$ da República.

BRASIL, Lei $n^{\circ} 7.803 / 89$, altera a redação da Lei $n^{\circ} 4.771$, de 15 de setembro de 1965 , e revoga as Leis $n^{\circ} \mathrm{s}$ 6.535, de 15 de junho de 1978, e 7.511, de 7 de julho de 1986. Congresso Nacional, Brasília, 18 de julho de 1989; 168 . da Independência e $101^{\circ}$ da República.

BRUNA, Gilda Collet. Questões de organização do espaço regional. São Paulo: Nobel: Ed. da Universidade de São Paulo, 1983.

CARVALHO, Pompeu Figueiredo. Repensando as áreas verdes urbanas. Rio Claro: Unesp, Território e Cidadania, 2003.

CAVALHEIRO, F. \& DEL PICCHIA, P.C.D. Áreas Verdes: conceitos, objetivos e diretrizes para o planejamento. In: Congresso Brasileiro sobre Arborização Urbana, I, Vitória/ES, 13-18/09/92. Anais I e II. 1992. p.29-35.

CORAZZA, Jaqueline. Morfologia urbana e microclima. Passo Fundo, 2003. Monografia (Especialização), FEAR, Universidade de Passo Fundo, 2003.

DAL MORO, Selina Maria; KALIL, Rosa Maria Locatelli; TEDESCO, João Carlos. Urbanização, exclusão e resistência: estudos sobre o processo de urbanização na região de Passo Fundo. Passo Fundo: Ediupf, 1998.

DIEHL, Astor Antônio. Passo Fundo: uma história, várias questões. Passo Fundo: EDIUPF, 1998.

FEIBER, Silmara Dias. Áreas Verdes Urbanas Imagem e Uso - O Caso do Passeio Público de Curitiba-Pr. R. RA'E GA, Curitiba, n. 8, p. 93-105, 2004. Editora UFPR.

FUNDAÇÃO DE ECONOMIA E ESTATÍSTICA. Resumo Estatístico RS. Disponível em < http://www.fee.tche.br>. Acesso em: 28 abril 2005.

GELPI, A; ROSSETTO, A. Planejamento e Educação Ambiental. In apostila de aula. Curso de Arquitetura e Urbanismo. Universidade de Passo Fundo. Passo Fundo, 1999. 
HAAS, Cristina. Paisagismo- Recomposição Ambiental. In. Minicurso de paisagismo - I Semana Acadêmica de Engenharia e Arquitetura. UPF. Passo Fundo, 1999.

HARD. Letícia Peret Antunes . Fundamentos técnicos. In: Curso de Paisagismo em Áreas Urbanas. Universidade Livre do Meio Ambiente. Paraná, 2002. p.28-57.

INSTITUTO BRASILEIRO DE GEOGRAFIA E ESTATÍSTICA. Cidades @. Disponível em <http://www.ibge.gov.br>. Acesso em: 25 abril 2005.

MAGALHÃES. Sérgio Ferraz. Favela, um bairro: propostas metodológicas para intervenção pública em favelas do Rio de Janeiro. São Paulo: Pro-Editores, 1996. 184 p.

MELLO,E.; CAÑELAS, K. Conceitos de paisagismo. In apostila de aula. Curso de Arquitetura e Urbanismo. Universidade de Passo Fundo. Passo Fundo, 2000.

MENEZES, C. L. Desenvolvimento urbano e meio ambiente: A experiência de Curitiba. Campinas: Papirus, 1996.

MILANO, M. S. O planejamento e replanejamento de arborização de ruas. In: Encontro nacional sobre arborização urbana, 2. 1987. Maringá, P.M.M. 1987. p. 01-08.

MORETTI, Ricardo de Souza. Normas urbanísticas para habitação de interesse social: recomendações para elaboração. São Paulo: Instituto de Pesquisas Tecnológicas, 1997.

OLIVEIRA, Lucimara Albieri. O papel da praça na cidade: aspectos ambientais, de uso e percepção. Passo Fundo, 2004. Dissertação (Mestrado), Faculdade de Arquitetura e Engenharia, Universidade de Passo Fundo, 2004.

PAIVA, E.; MACEDO, F.; RIBEIRO, D.; GRAEFF, E. Passo Fundo: Plano Diretor. Passo Fundo: Imprensa Oficial do Estado do Rio Grande do Sul, 1953.

PREFEITURA MUNICIPAL DE PASSO FUNDO. Planejamento. Disponível em <http://www.pmpf-rs.gov.br>. Acesso em: 25 abril 2005.

PUPPI, Ildefonso C. Estruturação sanitária das cidades. São Paulo: CETESB, 1981. 330 p.

REQUIXA, R. O lazer no Brasil. São Paulo: Brasiliense, 1977.

RODRIGUES. Ferdinando de Moura. Desenho urbano, cabeça, campo e prancheta. São Paulo: Projeto, 1986.

TOMASINI, Sérgio Luiz. A arborização de vias públicas no paisagismo urbano. In: Seminário Regional sobre paisagismo Urbano. 1998, Passo Fundo. Anais, Passo Fundo: UPF, 1998. p. 59-84. 